\title{
The Physicochemical Characteristics of Silicon-Germanium Nanoclusters
}

\author{
I. Zitouni*, K.E. Aiadi, O. Bentouila, M. Benaida, H. Bouguettaia, Z. Ayat \\ Laboratory of New and Renewable Energy in Arid and Saharan Zones - LENREZA, Ouargla University, \\ 30000 Ouargla, Algeria
}

(Received 21 April 2020; revised manuscript received 15 October 2020; published online 25 October 2020)

\begin{abstract}
A systematic investigation with density functional theory (DFT) was carried out in order to explore the structural, energetic and electronic properties of silicon-doped germanium ( $\mathrm{SiGe}_{n}, n=1-20$ ) clusters using SIESTA package. In this regard, isomers of $\mathrm{SiGe}_{n}$ clusters with the lowest-energy were determined and discussed. We found that the doping of $\mathrm{Ge}_{n+1}$ clusters with one $\mathrm{Si}$ atom enhances the stability of these clusters. The relative stability has been studied relative to cluster size in terms of binding energies, fragmentation energies and second-order difference of energies for all $\mathrm{SiGe}_{n}$ structures. Likewise, electronic properties such as HOMO-LUMO gaps, vertical electron affinity (VEA) and vertical ionization potential (VIP) were identified and analyzed as well. Maximum peaks of the fragmentation energy were observed at sizes $n=3,5,8-11,13,15$, and 17 for $\mathrm{Ge}_{n+1}$ and $\mathrm{SiGe}_{n}$ clusters, respectively, which indicates that these clusters have higher relative stability than their neighbors. Besides, the second energy difference analysis shows that $\mathrm{Ge}_{n+1}$ and $\mathrm{SiGe}_{n}$ clusters at $n=2-8,10-15,19,20$ are more stable. The values of HOMO-LUMO gaps take a decreasing trend with the increasing number of $\mathrm{Si}$ atoms in the cluster, which suggest an increase in chemical activity. Also, through our discussion of parameters VEA and VIP we found that $\mathrm{SiGe}_{4}$ cluster has high metallic property. The obtained results revealed that the $\mathrm{SiGe}_{15}$ cluster with $\mathrm{C}_{2}$ symmetry is more stable than the other clusters.
\end{abstract}

Keywords: Si-Ge clusters, DFT, Stabilities, Electronic properties, Structural properties.

\section{INTRODUCTION}

Nowadays, nanotechnology is a fast growing scientific and technical field. It is well established that at this scale, the behavior of matter gives rise to new fundamental properties that are vastly different from those of massive materials [1,2]. During the past decade, nanoclusters studying has attracted the attention of many researchers worldwide. Semiconductors have great importance in applications of electronic devices and optoelectronics as germanium is expected to be a probable alternative to silicon, especially in certain sectors of microelectronic industry [3]. The physicochemical properties of nanoclusters have been explored and studied experimentally and theoretically [4] worldwide. Shi et al. [5] have conducted a computational study of pure germanium and $\mathrm{AlGe}_{n}(n=1-9)$ clusters. The researchers found that the stability of $\mathrm{Ge}_{n+1}$ cluster was somewhat higher than that of $\mathrm{AlGe}_{n}$. Siouani et al. [6] have investigated the properties of pure and V-doped germanium clusters. They established that the dopant $\mathrm{V}$ intensely contributed in enhancing the stability for $n \geq 7$, but did not affect the stability of germanium clusters $(n<6)$. Likewise, Mahtout et al. [7] have regularly investigated the properties of $\mathrm{MGe}_{n}(\mathrm{M}=\mathrm{Au}, \mathrm{Cu}$ and $\mathrm{Ag})$ clusters. They figured out that the replacement of one $\mathrm{Ge}$ atom by a $\mathrm{Cu}$ one improved the stabilization of germanium clusters compared to Ag and Au. Djaadi et al. [8] have considered the magnetic properties and relative stability of pure and tin-doped germanium clusters $\mathrm{SnGe}_{n}(0, \pm 1) \quad(n=1-17)$. This attempt resulted that these clusters took compact geometries as the cluster size magnified. Benaida et al. [9] have proposed and carried out studies on geometry, electronic properties and stability of $\mathrm{Ge}_{n+1}$ and $\mathrm{AsGe}_{n}(0, \pm 1)$ clusters with size range $n=1-20$. They found out that the substitution of one germanium atom by arsenic did not ameliorate the stability of the germanium clusters. The main target of the present investigation is to study the effect of one $\mathrm{Si}$ atom on some properties such as structural, energetic, and electronic of germanium clusters $\mathrm{Ge}_{n+1}(n=1-20)$ within functional density theory (DFT) [10].

\section{COMPUTATIONAL METHODOLOGY}

Using functional density theory (DFT), electronic structure of $\operatorname{SiGe}_{n} q(n=1-20, q=0, \pm 1)$ clusters was computed and compared to pure germanium clusters $\mathrm{Ge}_{n+1}$. The calculations were effectuated using SIESTA package [11]. This program employs the normconserving Troullier-Martins nonlocal pseudopotentials method, and is based on PAO (pseudo-atomic orbits) [12]. The generalized gradient approximation (GGA) of Perdew-Burke-Ernzerhof [13] has been utilized for the exchange correlation energy. In this calculation, the double $\zeta$ (DZ) basis for both $\mathrm{Si}$ and Ge atoms was used with an energy shift equal to $50 \mathrm{meV}$. Moreover, we used the cubic supercell of $40 \AA$, where a periodic boundary condition was considered to evade interactions among adjacent clusters. The $k$ grid integration was conducted by using the $\Gamma$ point approximation. In addition, the conjugated gradient method within HellmannFeynman forces was utilized and, after structural relaxation, all forces were less than $10^{-3} \mathrm{eV} / \AA$. Based on a convergence criterion of $10^{-4}$ a.u. for the system's total energy, the self-consistent calculations were conducted.

\section{*Z.ikram30@gmail.com}


To start with, the most stable structure of pure germanium clusters $\mathrm{Ge}_{n}+1$ with size of $1-20$ atoms was found, as reported in our previous work [9]. Secondly, the possibilities of different isomers were determined and optimized for $\mathrm{SiGe}_{n}$ clusters by the substitution of one Ge atom by a $\mathrm{Si}$ one on distinct sites of the lowestenergy configuration of pure $\mathrm{Ge}_{n+1}$ clusters [9], so as to approach and access the ground states. In the following section, the best calculated structures are reported and discussed, taking into consideration only the most appropriate isomers defined for each cluster size in our optimizations. This mode was validated by calculations on $\mathrm{Ge}_{2}$ and $\mathrm{Si}_{2}$ clusters. The obtained results are displayed in Table 1 and confronted to previous theoretical and experimental data. It could be seen that the present results agree well with reported studies in literature, which emphasizes the efficiency of the adopted computational scheme.

Table 1 - Averaged bond length $a(\AA)$, binding energy $E_{b}(\mathrm{eV})$, vertical ionization potential VIP (eV) for $\mathrm{Ge}_{2}$ and $\mathrm{Si}_{2}$

\begin{tabular}{|c|c|c|c|c|c|c|}
\hline \multirow{2}{*}{ Symmetry } & \multicolumn{3}{|c|}{ Our work } & \multicolumn{3}{|c|}{ Bibliography data [5, 14-20] } \\
\hline & $a(\AA)$ & $E_{b}(\mathrm{eV})$ & VIP $(\mathrm{eV})$ & $a(\AA)$ & $E_{b}(\mathrm{eV})$ & VIP $(\mathrm{eV})$ \\
\hline $\mathrm{Ge}_{2}$ & 2.503 & 1.445 & 7.362 & $\begin{array}{l}2.440 \\
2.540 \\
2.570 \\
\end{array}$ & $\begin{array}{c}1.320 \\
\sim 1.350 \\
1.230\end{array}$ & $\begin{array}{l}7.627 \\
7.844\end{array}$ \\
\hline $\mathrm{Si}_{2}$ & 2.400 & 1.507 & 7.720 & $\begin{array}{l}2.266 \\
2.164 \\
2.303 \\
2.171 \\
2.166\end{array}$ & $\begin{array}{l}1.610 \\
1.980 \\
1.580\end{array}$ & $\begin{array}{l}7.900 \\
7.882 \\
7.856 \\
7.834\end{array}$ \\
\hline
\end{tabular}

\section{RESULTS AND DISCUSSION}

\subsection{Structural Properties}

Generally known, the study of properties of clusters normally commences with a structural analysis and an investigation of their geometries.

Searching for a lowest-energy structure is a very important process, and it is not easy to handle this task because the number of isomers raises in an exponential manner as the number of atoms in the cluster increases. The most appropriate structures of $\mathrm{SiGe}_{n}$ clusters were determined and presented in Fig. 1. Recently in an earlier publication [9] it was reported the ground state geometries of $\mathrm{Ge}_{n+1}(n=1-20)$. The ground state of SiGe dimer has a large binding energy (1.475 eV/atom) as compared with that of $\mathrm{Ge}_{2}$ dimer (1.445 eV/atom). The bond length of SiGe was calculated and found to be $2.454 \AA$. It was found that $\mathrm{SiGe}_{2}$ trimer presents a $\mathrm{C}_{2 \mathrm{v}}$ bent structure which is the lowest-energy structure. Additionally, in the earlier work [9], the ground state structure was obtained in the geometry of $\mathrm{Ge}_{3}$ which has the same symmetry.

The binding energy of the most stable $\mathrm{SiGe}_{3}$ structure with a planar $\mathrm{C}_{2 \mathrm{v}}$ symmetry is $2.611 \mathrm{eV} / \mathrm{atom}$. This value is relatively larger when compared to that of tetramer $\mathrm{Ge}_{4}$ (2.557 eV/atom) [9]. The lowest-energy geometry of the pentamer $\mathrm{SiGe}_{4}$ belongs to the structure composed of three triangles with $\mathrm{C}_{2}$ symmetry. The binding energy of this structure equals to $2.577 \mathrm{eV} /$ atom, which is lower than that of $\mathrm{Ge}_{5}$ [9]. SiGe5 cluster has a square bipyramidal structure with $\mathrm{C}_{\mathrm{s}}$ symmetry which is represented by the ground state isomer, where the length of $\mathrm{Si}-\mathrm{Ge}$ and $\mathrm{Ge}-\mathrm{Ge}$ bonds is $2.642 \AA$ and $2.835 \AA$, respectively. The substitution of a $\mathrm{Ge}$ atom by a $\mathrm{Si}$ one in the $\mathrm{Ge}_{7}$ structure with $\mathrm{D}_{5 \mathrm{~h}}$ symmetry [9] gives the most favorable isomer of $\mathrm{SiGe}_{6}$ which offers bicapped pentagonal structure with $\mathrm{C}_{5 \mathrm{v}}$ symmetry. Regarding $\mathrm{SiGe}_{7}$, the lowest-energy structure can give capped pentagonal bipyramidal geometry with $\mathrm{C}_{\mathrm{s}}$ symmetry. As for the size $n=8$, its computed binding energy is $3.012 \mathrm{eV} /$ atom. This is larger than that of Geg with $\mathrm{C}_{\mathrm{s}}$ symmetry of the most appropriate structure for SiGe8, whereas the bond lengths of Ge-Ge and Si-Ge are $2.766 \AA$ and $2.780 \AA$, respectively. The most favorable isomer for $\mathrm{SiGe}_{9}$ can be described as capped pentagonal geometry $\left(\mathrm{C}_{2 \mathrm{v}}\right)$. The mean $\mathrm{Si}-\mathrm{Ge}$ and Ge-Ge bond lengths are $2.780 \AA$ and $2.766 \AA$, respectively. For $n=10$, the lowest-energy isomer has $\mathrm{C}_{1}$ symmetry. The calculated $\mathrm{Si}-\mathrm{Ge}$ and $\mathrm{Ge}-\mathrm{Ge}$ bond lengths for $\mathrm{SiGe}_{10}$ are $2.765 \AA$ and $2.794 \AA$, respectively. The most appropriate geometry of SiGe11 presents prolate structure with $\mathrm{C}_{\mathrm{s}}$ symmetry. In this structure, a $\mathrm{Si}$ atom is located on the surface. It has bond lengths of $2.747 \AA$ and $2.674 \AA$ for Ge-Ge and Si-Ge, respectively. As for $n=12$, the ground state geometry is obtained by replacing the tetrahedrally coordinated capping Ge atom with a $\mathrm{Si}$ one. The binding energy of $\mathrm{SiGe}_{12}$ (3.063 eV/atom) is approximately equivalent to that obtained for the most favorable isomer of SiGe 11 cluster (3.062 eV/atom). For the subsequent cluster size $n=13$, the most stable geometry was found. It has a stack of two misrepresented rhombi and one fivefold ring capped with an atom, and has $\mathrm{C}_{1}$ point group symmetry, where the lengths of $\mathrm{Si}-\mathrm{Ge}$ and $\mathrm{Ge}-\mathrm{Ge}$ bonds are $2.765 \AA$ and $2.793 \AA$, respectively. The most appropriate structures for the sizes $n=14$ and 15 have similar shapes of $\mathrm{Ge}_{15}$ and $\mathrm{Ge}_{16}$ [9], respectively, such that the $\mathrm{Si}$ atom is located at the surface. The ground state isomer of $\mathrm{SiGe}_{14}$ has the bond length of $\mathrm{Ge}-\mathrm{Ge}$ and Si-Ge of $2.810 \AA$ and $2.787 \AA$, respectively. The lowestenergy isomer for SiGe15 with average Ge-Ge and Si-Ge has bond lengths of $2.792 \AA$ and $2.732 \AA$, respectively. As far as large clusters $(n \geq 16)$ are concerned, it has been demonstrated that they had distorted structures. The irregular cage-like structure SiGe 16 is found to be the most stable with $\mathrm{C}_{\mathrm{s}}$ symmetry. Its binding energy (0.025 eV/atom) is larger than that of $\mathrm{Ge}_{17}$ [9]. The ground state structure $\mathrm{SiGe}_{17}$ is made up of three connected pentagonal parties, a dimer and a capped tetragonal prism, nonetheless, this geometry is not a 
layered structure. For $n=18$, the steadiest structure of $\mathrm{SiGe}_{18}$ has an irregular cage-like structure with $\mathrm{C}_{1}$ symmetry. Its binding energy (3.069 eV/atom) is somewhat smaller than that of the steadiest isomer of $\mathrm{SiGe}_{17}$. In the most appropriate structure for $\mathrm{SiGe}_{19}$, it has average distances of $2.736 \AA$ and $2.660 \AA$ for Ge-Ge and $\mathrm{Si}-\mathrm{Ge}$, respectively, with $\mathrm{C}_{1}$ point group symmetry.
The binding energy of SiGe19 was computed and found to be $3.063 \mathrm{eV} /$ atom. For $n=20$, our calculations show that SiGe20, a combination of a prolate-like structure with the cage-like one, is a ground state structure with $\mathrm{C}_{1}$ symmetry. The binding energy of SiGe20 cluster is $3.076 \mathrm{eV} /$ atom. This value is high when compared to that of $\mathrm{Ge}_{21}$ (3.061 V/atom) [9].
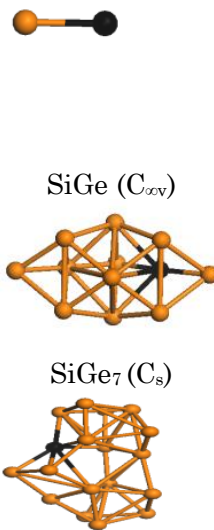
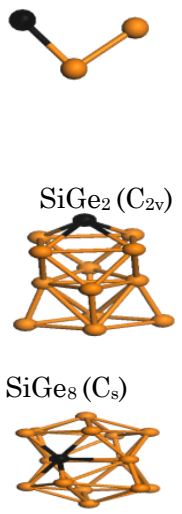

$\operatorname{SiGe}_{14}\left(\mathrm{C}_{\mathrm{s}}\right)$

$\operatorname{SiGe}_{15}\left(\mathrm{C}_{2}\right)$
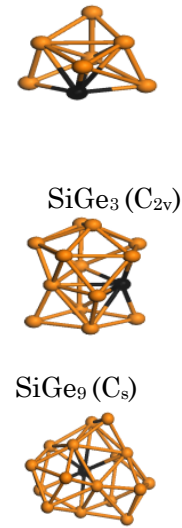

$\operatorname{SiGe}_{16}\left(\mathrm{C}_{\mathrm{s}}\right)$

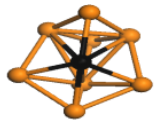

$\mathrm{SiGe}_{4}\left(\mathrm{C}_{2}\right)$
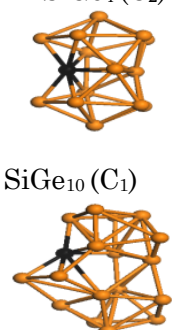

$\operatorname{SiGe}_{17}\left(\mathrm{C}_{1}\right)$
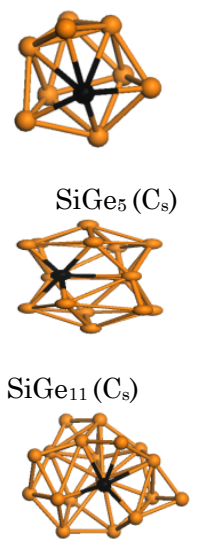

$\operatorname{SiGe}_{18}\left(\mathrm{C}_{1}\right)$

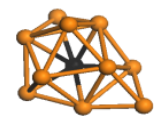

$\mathrm{SiGe}_{6}\left(\mathrm{C}_{5 \mathrm{v}}\right)$
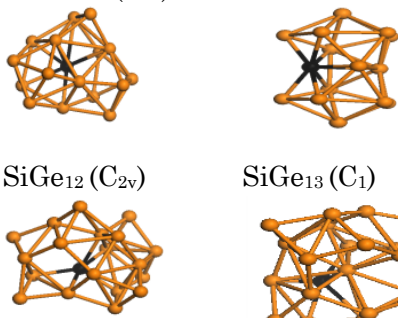

$\operatorname{SiGe}_{13}\left(\mathrm{C}_{1}\right)$

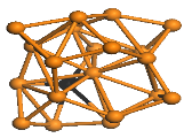

$\operatorname{SiGe}_{19}\left(\mathrm{C}_{1}\right)$

$\operatorname{SiGe}_{20}\left(\mathrm{C}_{1}\right)$

Fig. 1 - Most appropriate structures of $\operatorname{SiGe}_{n}(n=1-20)$ clusters

\subsection{Energetic Properties}

\subsubsection{Binding Energy $E_{b}$}

So as to corroborate the stability of $\operatorname{SiGe}_{n}(0, \pm 1)$ clusters, the binding energy of the most stable isomers was calculated. Fig. 2 shows comparison between the evolution of binding energies with the cluster size for $\mathrm{Ge}_{n+1}$ and $\operatorname{SiGe}_{n}(n=1-20)$ clusters. As expected, the binding energy per atom augments as the size of $\mathrm{SiGe}_{n}$ and $\mathrm{Ge}_{n+1}$ clusters increases. During the growth process, both clusters can acquire energy constantly. It could be observed in Fig. 2 that the binding energy per atom of $\mathrm{SiGe}_{n}$ clusters is larger than those of corresponding pure $\mathrm{Ge}_{n+1}$ clusters, except for $n=4$. This means that the replacement of a Ge atom by a Si one has enhanced the stability of germanium clusters. Furthermore, the value of the binding energy increased from 2.215 eV/atom for $n=2$ in $\mathrm{SiGe}_{n}$ cluster and reached its highest value of $3.076 \mathrm{eV} / \mathrm{atom}$ in $\mathrm{SiGe}_{20}$.

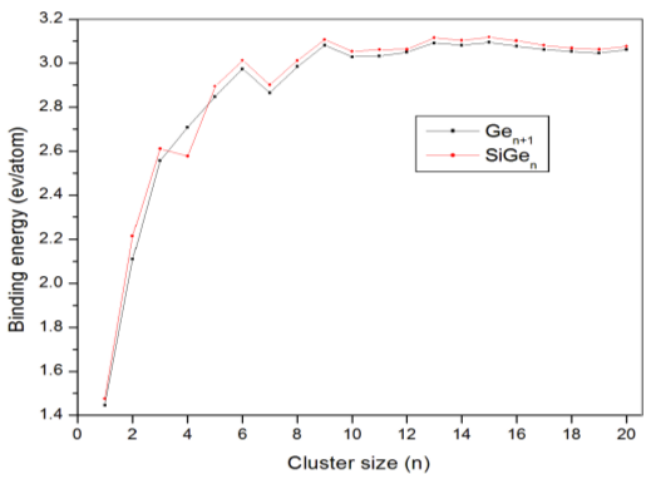

Fig. 2-Growth of the binding energy for the lowest-energy structures of $\mathrm{Ge}_{n+1}$ and $\mathrm{SiGe}_{n}(n=1-20)$ clusters

\subsubsection{Fragmentation Energy $E_{f}$}

Fig. 3 presents fragmentation energy evolution against cluster size for the most appropriate structures of $\mathrm{Ge}_{n+1}$ and $\mathrm{SiGe}_{n}(n=1-20)$ clusters, where an oscillating behavior was observed of that curve. As known in cluster physics, the clusters with big fragmentation energy value are relatively strong in thermodynamic stability. Consequently, the thermodynamic stability of clusters such as, $\mathrm{Ge}_{5}, \mathrm{Ge}_{8}, \mathrm{Ge}_{10}, \mathrm{Ge}_{11}, \mathrm{Ge}_{15}, \mathrm{Ge}_{17}, \mathrm{SiGe}_{3}$, $\mathrm{SiGe}_{5}, \mathrm{SiGe}_{9}$ and $\mathrm{SiGe}_{13}$ is somewhat stronger than that of their neighboring ones.

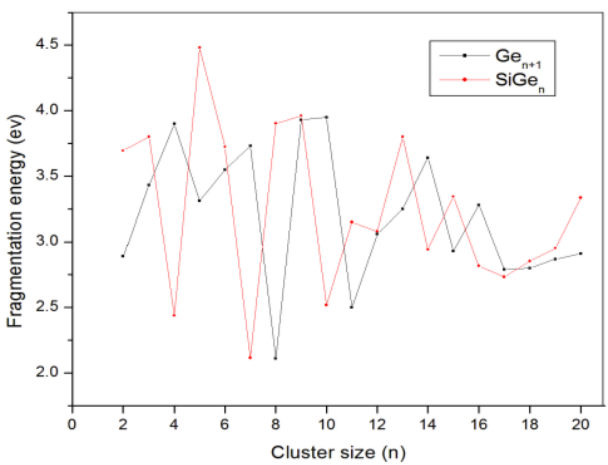

Fig. 3 - Growth of the fragmentation energy for the lowestenergy structures of $\mathrm{Ge}_{n+1}$ and $\operatorname{SiGe}_{n}(n=1-20)$ clusters

\subsubsection{Second-order Difference $\Delta_{2} E$}

The second-order difference of the total energy is a very significant factor in the cluster physics domain, where it shows the stability for electronic structures of clusters. Besides, the clusters having a negative $\Delta_{2} E$ are less stable than those having a positive $\Delta_{2} E$. The size dependence of the calculated second-order differ- 
ence of energies for ground state isomers is plotted in Fig. 4. In the general trend of the curves, it is observed that they present oscillations and very prominent peaks at the range sizes $n=2,4,7,10,12,14$, and 19 atoms for $\mathrm{SiGe}_{n}$ and at $n=2,3,5,6,8,11,12,13,15$, and 20 for $\mathrm{Ge}_{n+1}$. This indicates that these clusters are more stable than the others.

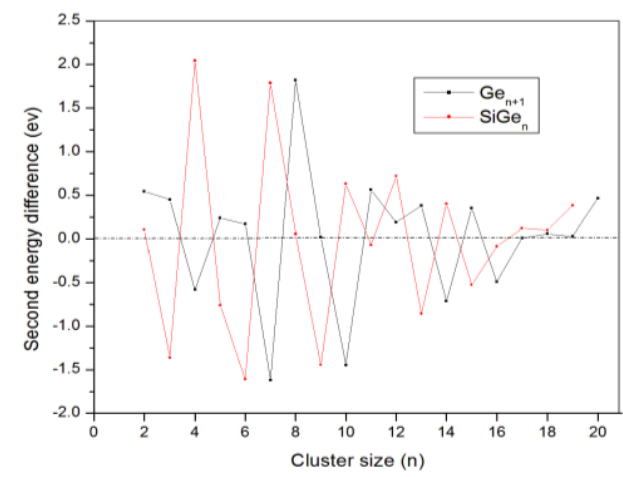

Fig. 4 - Growth of the second energy difference for the lowestenergy structures of $\mathrm{Ge}_{n+1}$ and $\mathrm{SiGe}_{n}(n=1-20)$ clusters

\subsection{Electronic Properties}

\subsubsection{HOMO-LUMO Gap $\Delta E$}

Another important physical parameter that affects cluster properties is the HOMO-LUMO gap. It represents the capability of the cluster to engage in chemical reactions. Besides, it is a significant characteristic in terms of cluster electronic stability. In Fig. 5, we have plotted the cluster size as a function of the HOMOLUMO gap $(\Delta E)$ for all the most appropriate clusters. In general, we note that the HOMO-LUMO gap in the studied structures of both $\mathrm{Ge}_{n}+1$ and $\mathrm{SiGe}_{n}$ tends to decrease when the size of the clusters increases with some conformance. Furthermore, the clusters $\mathrm{Ge}_{n+1}$ and $\mathrm{SiGe}_{n}$ of sizes $n=2,5,6,8,9,11,13,15$, and 17 have large values for the HOMO-LUMO gaps, which indicates that these clusters are chemically less active. Moreover, the HOMO-LUMO gap of the $\mathrm{SiGe}_{4}$ is less than $\mathrm{Ge}_{5}$, which means that the doping of $\mathrm{Si}$ enhances the chemical activity of this cluster.

\subsubsection{Vertical Electronic Affinity (VEA) and Vertical Ionization Potential (VIP)}

The chemical stability of the clusters can be characterized by the vertical electron affinity (VEA) and the vertical ionization potential (VIP) parameters. Fig. 6 shows increasing VEA evolution relative to cluster size. It was observed that $\mathrm{SiGe}_{4}$ cluster can capture an electron more facilely with energy liberate. The VIP values are plotted as a function of size in Fig. 7. Oscillating behavior and reduction in VIP values are observed relative to cluster size. VIP is an indicator that determines the metallic character of the clusters. The cluster is more near to a metallic character when the VIP value becomes smaller. This is achieved through $\mathrm{SiGe}_{4}$ cluster $(6.969 \mathrm{eV})$, which exhibits high metallic character. The large VIP values of SiGe clusters indicate less potential for ionization and hence, higher stability than their neighbors.

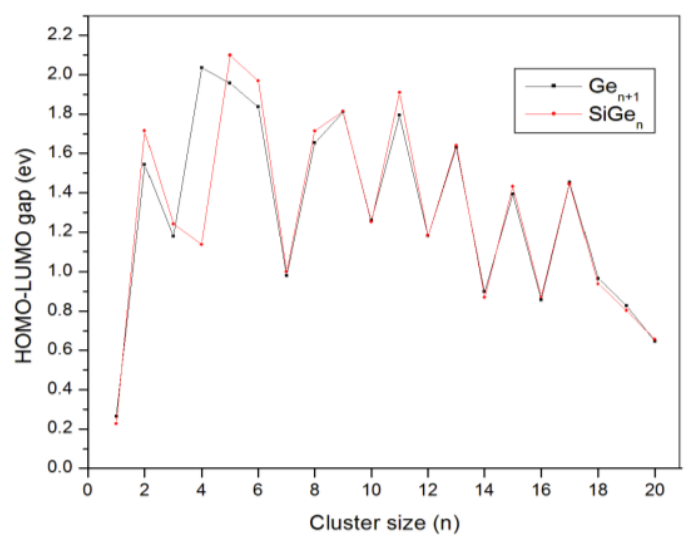

Fig. 5 - Growth of the HOMO-LUMO gaps for the lowestenergy structures of $\mathrm{Ge}_{n+1}$ and $\operatorname{SiGe}_{n}(n=1-20)$ clusters

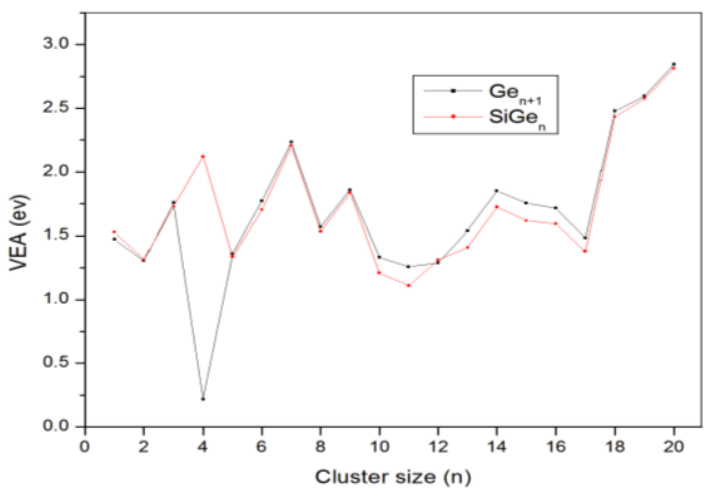

Fig. 6 - Growth of the vertical electron affinity (VEA) for the lowest-energy structures of $\mathrm{Ge}_{n+1}$ and $\mathrm{SiGe}_{n}$ clusters

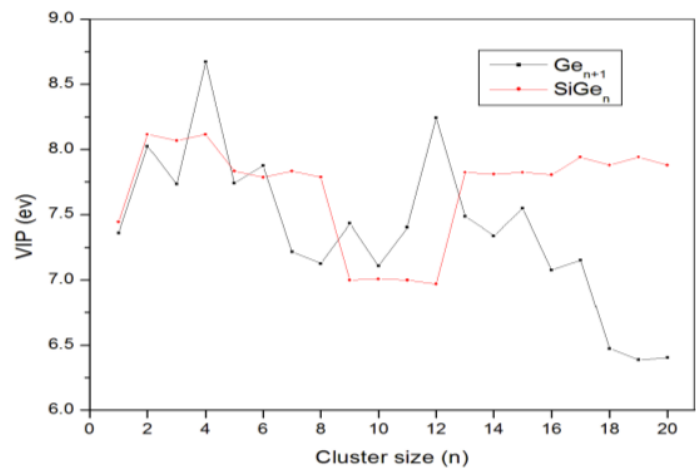

Fig. 7 - Growth of the vertical ionization potential (VIP) for the lowest-energy structures of $\mathrm{Ge}_{n+1}$ and $\mathrm{SiGe}_{n}(n=1-20)$ clusters

\section{CONCLUSIONS}

In this work we used density functional theory (DFT) in order to stabilize and to bring out the electronic properties of $\operatorname{SiGe}_{n}(n=1-20)$. After studying the cluster's structures, it was established that the dopant atom $\mathrm{Si}$ is situated on the surface of the germanium cage for most clusters sizes. To study the relative stability, the binding energy was calculated, and it was found that it increases with increasing size of both $\mathrm{Ge}_{n+1}$ and $\mathrm{SiGe}_{n}$ clusters. It was also deduced that doping with $\mathrm{Si}$ atom enhances the stability of the $\mathrm{Ge}_{n+1}$ clusters. Furthermore, the fragmentation energies and second-order difference of energies, HOMO-LUMO en- 
ergy gaps, vertical ionization potentials, vertical electron affinities were also taken into consideration, therefore, computed and studied. Among the discussed clusters, SiGe5 cluster with $\mathrm{C}_{\mathrm{s}}$ symmetry, that shows less reactivity and more stability than its neighbors due to its large HOMO-LUMO gap. This work is an exploratory study in this field which can give insight into future experimental studies.

\section{REFERENCES}

1. A.A. Shvartsburg, B. Liu, Z.Y. Lu, Cai-Zhuang Wang, M.F. Jarrold, K.-M. Ho, Phys. Rev. Lett. 83 No 11, 2167 (1999).

2. P.N. Samanta, K.K. Das, Comput. Theor. Chem. 980, 123 (2012).

3. Y.N. Palyanov, I.N. Kupriyanov, Y.M. Borzdov, N.V. Surovtsev, Sci. Rep. 5, 14789 (2015).

4. S. Jaiswal, V. Kumar, Comp. Theo Chem. 1075, 87 (2016).

5. S. Shi, Y. Liu, C. Zhang, B. Deng, G. Jiang, Comp. Theo Chem. 1054, 8 (2015).

6. C. Siouani, S. Mahtout, S. Safer, F. Rabilloud, J. Phys. Chem. A 121 No 18, 3540 (2017).

7. S. Mahtout, C. Siouani, F. Rabilloud, J. Phys. Chem. A 122 No 2, 662 (2018).

8. S. Djaadi, K.E. Aiadi, S. Mahtout, J. Semicond. 39 No 4, 042001 (2018)

9. M. Benaida, K.E. Aiadi, S. Mahtout, S. Djaadi, W. Rammal, M. Harb, J. Semicond. 40 No 3, 032101 (2019).

10. P. Ordejón, E. Artacho, J.M. Soler, Phys. Rev. B 53 No 16, R10441 (1996).

\section{ACKNOWLEDGEMENTS}

The authors would like to thank the staff of the LENREZA laboratory for their assistance and encouragement throughout this study. Deep and sincere gratitude should be extended to Prof. Hamza Bouguettaia, Department of Physics, K.M. University, Ouargla, Algeria, for his help in this article.

11. J.M. Soler, E. Artacho, J.D. Gale, A. García, J. Junquera, P. Ordejón, D. Sánchez-Portal, J. Phys. Cond. Matter. 14 No 11, 2745 (2002).

12. N. Troullier, J.L. Martins, Phys. Rev. B 43 No 3, 1993 (1991).

13. J.P. Perdew, K. Burke, Phys. Rev .Lett. 77 No 18, 3865 (1996).

14. D. Bandyopadhyay, P. Sen, J. Phys. Chem. A. 114 No 4, 1835 (2010).

15. S. Nagendran, S.S. Sen, H.W. Roesky, D. Koley, H. Grubmüller, A. Pal, R. Herbst-Irmer, Organometallics 27 No 21, 5459 (2008).

16. J. Wang, G. Wang, J. Zhao, Phys. Rev. B 64 No 20, 205411 (2001).

17. P. Wielgus, S. Poszak, D. Majumdar, J. Saloni, J. Leszczynski, J. Chem. Phys. 128 No 14, 144305 (2008).

18. C. Sporea, F. Rabilloud, X. Cosson, A.R. Allouche, M. AubertFrécon, J. Phys. Chem. A 110 No 18, 6032 (2006).

19. J.C. Grossman, L. Mitas, Phys. Rev. Lett. 74 No 8, 1323 (1995).

20. A. Kant, B.H. Strauss, J. Chem. Phys. 45 No 3, 822 (1966).

\title{
Фізико-хімічні характеристики нанокластерів кремнію-германію
}

\author{
I. Zitouni, K.E. Aiadi, O. Bentouila, M. Benaida, H. Bouguettaia, Z. Ayat \\ Laboratory of New and Renewable Energy in Arid and Saharan Zones - LENREZA, Ouargla University, \\ 30000 Ouargla, Algeria
}

\begin{abstract}
Проведено систематичне дослідження за допомогою функціональної теорії щільності (DFT) з метою вивчення структурних, енергетичних та електронних властивостей кластерів германію, легованих кремніем ( $\left.\mathrm{SiGe}_{n}, n=1-20\right)$, використовуючи програмне забезпечення SIESTA. У зв'язку з цим були визначені та обговорені ізомери кластерів $\mathrm{SiGe}_{n}$ з найнижчою енергією. Ми виявили, що легування кластерів $\mathrm{Ge}_{n+1}$ одним атомом $\mathrm{Si}$ підвищуе стійкість цих кластерів. Вивчено відносну стійкість розміру кластера в залежності від енергій зв’язку, енергій фрагментації та різниці енергій другого порядка для всіх структур $\mathrm{SiGe}_{n}$. Так само були визначені та проаналізовані електронні властивості, такі як зони HOMO-LUMO, вертикальна спорідненість до електронів (VEA) та вертикальний потенщіал іонізації (VIP). Максимальні піки енергії фрагментації спостерігалися при значеннях $n=3,5,8-11,13,15$ i 17 для кластерів $\mathrm{Ge}_{n+1}$ i $\mathrm{SiGe}_{n}$ відповідно, що вказуе на те, що ці кластери мають більш високу відносну стійкість, ніж їхні сусіди. Крім того, аналіз різниці енергій другого порядка показуе, що кластери $\mathrm{Ge}_{n+1}$ i $\mathrm{SiGe}_{n}$ при $n=2-8,10-15,19,20$ є більш стійкими. Значення зон HOMO-LUMO мають тенденщію до зменшення зі збільшенням кількості атомів $\mathrm{Si}$ в кластері, що говорить про збільшення хімічної активності. Крім того, через обговорення параметрів VEA та VIP ми виявили, що кластер $\mathrm{SiGe}_{4}$ має високу металеву властивість. Отримані результати показали, що кластер $\mathrm{SiGe}_{15} 3$ симетрією $\mathrm{C}_{2}$ більш стійкий, ніж інші кластери.
\end{abstract}

Ключові слова: Кластери Si-Ge, DFT, Стабільність, Електронні властивості, Структурні властивості. 